University of Nebraska - Lincoln

DigitalCommons@University of Nebraska - Lincoln

Relationship of cooked-rice nutritionally important starch fractions with other physicochemical properties

James Patindol

USDA-ARS, james.patindol@ars.usda.gov

Harmeet Guraya

USDA-ARS

Elaine Champagne

USDA-ARS

Ming-Hsuan Chen

USDA-ARS

Anna McClung

USDA-ARS

Follow this and additional works at: https://digitalcommons.unl.edu/usdaarsfacpub

Part of the Agricultural Science Commons

Patindol, James; Guraya, Harmeet; Champagne, Elaine; Chen, Ming-Hsuan; and McClung, Anna, "Relationship of cooked-rice nutritionally important starch fractions with other physicochemical properties" (2011). Publications from USDA-ARS / UNL Faculty. 577.

https://digitalcommons.unl.edu/usdaarsfacpub/577

This Article is brought to you for free and open access by the U.S. Department of Agriculture: Agricultural Research Service, Lincoln, Nebraska at DigitalCommons@University of Nebraska - Lincoln. It has been accepted for inclusion in Publications from USDA-ARS / UNL Faculty by an authorized administrator of DigitalCommons@University of Nebraska - Lincoln. 
Research Article

\title{
Relationship of cooked-rice nutritionally important starch fractions with other physicochemical properties*
}

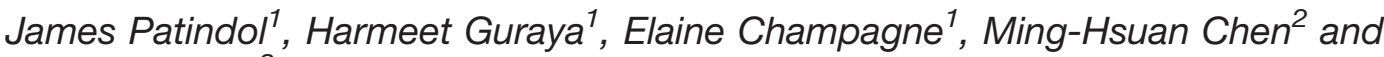 \\ Anna McClung ${ }^{3}$ \\ 1 USDA-ARS, Southern Regional Research Center, New Orleans, LA, USA \\ 2 USDA-ARS, Rice Research Unit, Beaumont, TX, USA \\ ${ }^{3}$ USDA-ARS, Dale Bumpers National Rice Research Center, Stuttgart, AR, USA
}

\begin{abstract}
Sixteen rice cultivars representing five cytosine-thymine repeat $\left(\mathrm{CT}_{n}\right)$ microsatellite genetic marker groups were analyzed for their cooked rice nutritionally important starch fractions (NISFs, which include rapidly digestible (RDS), slowly digestible (SDS), and resistant starch (RS)), basic grain quality indices (apparent amylose (AM), crude protein (CP), alkali spreading value (AS), and gel consistency (GC)), pasting characteristics, and thermal properties. Chemometric tools (bivariate correlation, principal component analysis, multiple linear regression, and partial least squares regression) were used to establish the association of NISF with other milled rice physicochemical properties. $\mathrm{CT}_{11}$ was generally associated with high percentages of RS and SDS, and a low percentage of RDS. $\mathrm{CT}_{14}$ was associated with low SDS; whereas, $\mathrm{CT}_{17}$ and $\mathrm{CT}_{18}$ were associated with low RS. The $\mathrm{CT}_{20}$ cultivars were similar to $\mathrm{CT}_{11}$ in SDS and RS; and to $\mathrm{CT}_{14}, \mathrm{CT}_{17}$, and $\mathrm{CT}_{18}$ in RDS content. RDS, SDS, and RS were loaded on three different quadrants of the principal component similarity map. RDS was not significantly correlated with any of the physicochemical properties; whereas, SDS was positively correlated with GC. RS was positively correlated with AM, setback (SB) viscosity, total setback (TSB) viscosity, and peak gelatinization temperature; and negatively correlated with breakdown (BD) viscosity. Multivariate techniques indicated lack of robustness in predicting RDS and SDS as the models only explained $<50 \%$ of the variance. More robust regression models were obtained for RS, explaining $>60 \%$ of its variation. Basic grain quality indices explained NISF variations better than pasting and thermal properties.
\end{abstract} Accepted: December 28, 2009

\section{Keywords:}

Amylose / Chemometrics / Nutrition / Rice / Starch digestibility

Correspondence: Dr. James Patindol, USDA-ARS, Southern Regional Research Center, PO Box 19687, New Orleans, LA 70179, USA

E-mail: james.patindol@ars.usda.gov

Fax: 504-286-4430.

Abbreviations: AM, apparent amylose; AS, alkali spreading value; $\mathbf{B D}$, breakdown; $\mathbf{C P}$, crude protein; $\mathbf{C T}$, conclusion temperature; $\mathbf{C T}_{\mathrm{n}}$, cytosine-thymine repeat; $\mathbf{F V}$, final viscosity; GC, gel consistency; GE, gelatinization enthalpy; GR, gelatinization range; HPV, hot paste viscosity; HSD, honestly significant difference; NISF, nutritionally important starch fraction; OT, gelatinization onset; PC, principal component; PLS, partial least square; PT, peak temperature; PV, peak viscosity; RDS, rapidly digestible starch; RMSE, root mean square error; $\mathbf{R S}$, resistant starch; RVA, Rapid Visco Analyzer; RVU, rapid viscounit; SB, setback; SDS, slowly digestible starch; TS, total starch; TSB, total setback.

*The mention of firm names or trade products does not imply that they are endorsed or recommended by the U.S. Department of Agriculture over other firms or similar products not mentioned. 


\section{Introduction}

Anent nutrition and health, starches in food are generally classified into rapidly digestible (RDS), slowly digestible (SDS), and resistant starch (RS). RDS is the fraction that is hydrolyzed to glucose within $20 \mathrm{~min}$; SDS is converted to glucose between 20 and 120 min; whereas, RS remains undigested after $120 \mathrm{~min}$ [1]. SDS goes through a slow but complete hydrolysis in the small intestine and its potential health benefits are linked to a stable glucose metabolism, diabetes management, mental performance, and satiety [2]. RS escapes digestion in the small intestine but is partially or entirely fermented in the colon. It shows promising physiological impact in the prevention of colon cancer, postprandial glycemia and insulinemia, hyperlipidemia, gall stone formation, and cardiovascular diseases [3].

Available methods for the determination of nutritionally important starch fractions (NISFs, i.e., RDS, SDS, and RS) are tedious and time consuming. Developing simple, fast, and accurate estimators will be a valuable innovation. It will also further our understanding of the genetic and chemical factors that influence NISF. In the case of rice, most cooking applications involve the use of whole grains so it is relevant to determine NISF in cooked rice as eaten. Cooked rice quality is primarily gauged by apparent amylose (AM) content [4]. As quality tends to vary among cultivars with similar amylose content, certain secondary parameters have been used for improved differentiation, such as protein content, alkali spreading value (AS), gel consistency (GC), viscosity, and pasting properties with a Brabender or a Rapid Visco Analyzer (RVA), and thermal characteristics with a differential scanning calorimeter [4].
Likewise, the use of microsatellite genetic markers as rice grain quality indicators is becoming popular and has been found useful in categorizing rice according to cooking and processing quality [5-8].

Previous works have shown that RS is positively correlated with amylose content [4, 9-14]. Hu et al. [15] identified a high-amylose rice cultivar with low paste viscosity profiles (peak, hot paste, and cool paste) but high in RS. On the contrary, a recent study on rice starch indicated that breakdown (BD) viscosity correlated positively with RDS, negatively with SDS, and insignificantly with RS [16]. Literature is lacking concerning potential associations of cooked rice NISF with secondary rice quality indices (e.g., viscosity and pasting characteristics, thermal properties, and genetic markers). Hence, it will be meaningful to examine such correlations more carefully through the use of chemometrics. Chemometrics is a specialized discipline for extracting information from multivariate chemical data using tools of statistics and mathematics [17]. In the present work, it was hypothesized that aside from amylose, some of the commonly used secondary parameters of rice quality may be valuable predictors of cooked rice NISF.

\section{Materials and methods}

\subsection{Rice samples}

Sixteen rice cultivars were evaluated as part of the 2007 Uniform Regional Rice Nursery conducted in Stuttgart, Arkansas and Beaumont, Texas (Table 1). The field study was conducted as a randomized complete block design

Table 1. Grain type, genotype ( $\mathrm{CT}_{n}$ repeat), and amylose class of the rice samples

\begin{tabular}{llll}
\hline Cultivar & Grain type & $\mathrm{CT}_{n}$ repeat & a) Amylose class \\
\hline Arborio & Medium & 18 & Low (12.9) \\
Bengal & Medium & 18 & Low (10.0) \\
Bowman & Long & 11 & High (27.3) \\
Cheniere & Long & 20 & High (28.4) \\
Cocodrie & Long & 20 & High (28.6) \\
Dixiebelle & Long & 11 & High (28.9) \\
HB-1 & Long & 17 & Waxy (0.3) \\
Hidalgo & Long & 18 & Low (10.5) \\
Jupiter & Medium & 17 & Low (12.6) \\
L205 & Long & 11 & High (27.1) \\
Rondo & Long & 11 & High (26.4) \\
Sabine & Long & 11 & High (28.3) \\
Sierra & Long & 11 & High (31.4) \\
Tesanai 2 & Medium & 11 & High (26.7) \\
Wells & Long & 14 & Intermediate (21.8) \\
XP723 & Long & $14: 20$ & Intermediate (20.1) \\
\end{tabular}

a) Value in parenthesis is average amylose content (\% dry basis) of Texas sample. 
with two field replications. Head rice samples were produced from $125 \mathrm{~g}$ of rough rice harvested from the plots as they approached 18-22\% MC. Samples were genotyped according to cytosine-thymine repeats $\left(\mathrm{CT}_{n} \mathrm{~s}\right)$ using the whole kernel alkali DNA extraction method [5-7] and Waxy RM190 microsatellite $\mathrm{CT}_{n}$ markers [5]. Grain type was determined based on grain length/width ratios of $\geq 3.0$ for long, 2.0-2.9 for medium, and $<2.0$ for short measured using a WinSeedle Pro $2005 \mathrm{a}^{\mathrm{TM}}$ image analysis system (Regent Instruments, Sainte-Foy, Quebec, Canada).

\subsection{Basic grain quality indices}

Head rice was ground into flour with a cyclone sample mill (Udy Corp., Fort Collins, CO, USA) fitted with a 0.50-mm screen. AM content on flour samples was determined by iodine colorimetry [18]. Samples were classified based on AM as follows: $0-2 \%$ (waxy), 2-12\% (very low), 12-20\% (low), 20-25\% (intermediate), and 25-33\% (high). Crude protein (CP) content was measured by combustion method on a nitrogen analyzer (FP-428, LECO, St. Joseph, MI, USA). A factor of 5.95 was used for converting nitrogen content to protein. Moisture content was determined by the AACC Method 44-15A [19]. AM and CP were expressed as percent dry basis. GC was determined according to Cagampang et al. [20] with modifications. A 25-mg rice flour sample was weighed into a $10 \mathrm{~mm} \times 75 \mathrm{~mm}$ test tube, wetted with $50 \mu \mathrm{L}$ of thymol blue solution $(0.025 \%$ thymol blue in $85 \%$ ethanol), and vortexed for $10 \mathrm{~s}$. It was immediately added with $0.5 \mathrm{~mL}$ of $0.2 \mathrm{~N} \mathrm{KOH}$, covered with marble, and heated in a boiling water bath for $7 \mathrm{~min}$. The water level of the bath was maintained to cover the lower $1 / 3$ of the tube. The tube was taken out, cooled at room temperature for $5 \mathrm{~min}$, and then chilled in an ice water bath $\left(8-9^{\circ} \mathrm{C}\right)$ for $10 \mathrm{~min}$. The chilled test tube was laid horizontally on a table for $30 \mathrm{~min}$ and the length of gel was measured (in $\mathrm{mm}$ ) from the bottom of the tube to the top of the gel. AS was determined following the method of Little et al. [21]. Six whole rice kernels were spaced evenly in a $60 \mathrm{~mm} \times 15 \mathrm{~mm}$ transparent plastic culture dish. Ten milliliter of $1.7 \%$ potassium hydroxide was added to immerse the grains. The dish was covered and left undisturbed at room temperature for $23 \mathrm{~h}$. The extent of spreading was rated using a 7-point numerical scale as follows: 1-grain not affected; 2-grain swollen; 3-grain swollen, with incomplete and narrow collar; 4-grain swollen, with complete and wide collar; 5-grain split or segmented, with complete and wide collar; 6-grain dispersed and merging with collar; and 7-grain completely dispersed and intermingled.

\subsection{Thermal properties}

Thermal properties were assessed with a multi-cell differential scanning calorimeter (TA Instruments, New Castle,
DE, USA). In a stainless steel ampoule, a 300-mg head rice sample ( $\sim 15$ grains) was added with $600 \mu \mathrm{L}$ deionized water, tightly sealed, equilibrated for $30 \mathrm{~min}$ at room temperature, and heated from 25 to $140^{\circ} \mathrm{C}$ at a rate of $2^{\circ} \mathrm{C} / \mathrm{min}$. Water was used in running the baseline and baseline subtractions were made on the thermal curves of the samples. Thermal transitions were defined in terms of gelatinization enthalpy (GE), range (GR), onset (OT), peak (PT), and conclusion (CT) temperatures. GR was obtained as the difference between CT and OT. The software Universal Analysis 2000 (TA Instruments) was used in the data acquisition.

\subsection{Pasting properties}

Pasting properties were measured with an RVA (Model 4, Newport Scientific, Warriewood, New South Wales, Australia) according to AACC Approved Method 61-02 [19]. Rice flour (3.0 g, 12\% moisture) was weighed into an RVA aluminum canister and $25 \mathrm{~g}$ of distilled water was added. The sample was first held for $1.5 \mathrm{~min}$ at $50^{\circ} \mathrm{C}$, heated to $95^{\circ} \mathrm{C}$ at $12^{\circ} \mathrm{C} / \mathrm{min}$, held for $2.0 \mathrm{~min}$ at $95^{\circ} \mathrm{C}$, cooled to $50^{\circ} \mathrm{C}$ at $12^{\circ} \mathrm{C} / \mathrm{min}$, and finally held for $1.5 \mathrm{~min}$ at $50^{\circ} \mathrm{C}$. The temperature corresponding to the initial increase in viscosity was designated as pasting temperature. Viscosity values were recorded in rapid visco-units (RVUs), in which $1 \mathrm{RVU}$ is equivalent to12 centipoise. The viscosity variables measured were: peak viscosity (PV), hot paste viscosity (HPV or trough), final viscosity (FV), $B D$, setback (SB), and total setback (TSB). BD was calculated as PV minus HPV; SB as FV minus PV; and TSB as FV minus HPV.

\subsection{Cooking rice and starch digestibility assay}

Head rice $(5 \mathrm{~g})$ was weighed into a long-type $150 \mathrm{~mL}$ beaker, added with $10 \mathrm{~mL}$ of deionized water, and allowed to stand for $15 \mathrm{~min}$. The beaker was transferred into a home-style rice cooker with the inner pan containing $175 \mathrm{~mL}$ of deionized water, and then steam-cooked until automatic shutoff (about $25 \mathrm{~min}$ ). Only four samples (in separate beakers) were cooked at a time to minimize variation in the subsequent analyses due to time factor. Cooked rice samples were allowed to cool inside the rice cooker for $15 \mathrm{~min}$ prior to analyses. To simulate a wellchewed sample, cooked rice was minced by passing it through a garlic press (GRIP-EZ ${ }^{\mathbb{R}}$, Norpro, Everett, WA, USA) that has 61 holes $(2.0 \mathrm{~mm}$ in diameter) on its base, three times. The different starch fractions (total starch (TS), RDS, SDS, and RS) were analyzed in vitro according to the Englyst et al. [1] method with modifications.

A $0.50 \mathrm{~g}$ minced freshly cooked rice sample (in duplicate) was weighed into a 50-mL graduated conical, screwcap centrifuge tube, and $25 \mathrm{mg}$ of guar gum, a 
$12.7 \mathrm{~mm} \times 3 \mathrm{~mm}$ magnetic stir bar, and $10 \mathrm{~mL}$ of acetate buffer $(0.1 \mathrm{M}, \mathrm{pH}=5.2)$ were added. The tube was capped and incubated in a water bath at $37^{\circ} \mathrm{C}$ with stirring at $160 \mathrm{rpm}$ for $10 \mathrm{~min}$, and then treated with $2.5 \mathrm{~mL}$ of amylase cocktail $(3800 \mathrm{U} / \mathrm{mL}$ pancreatin, $188 \mathrm{U} / \mathrm{mL}$ invertase, $13 \mathrm{U} / \mathrm{mL}$ amyloglucosidase from Sigma-Aldrich, St. Louis, MO, USA). The water bath set-up consisted of a $190 \times 100$ crystallizing dish half-filled with deionized water and fitted with a centrifuge tube rack to hold the samples in place. The dish was heated atop a digital hot plate/stirrer (Dataplate PMC 720 Series, Barnstead International, Dubuque, IA, USA) equipped with a temperature probe to regulate the water temperature. RDS and SDS were determined on $0.25 \mathrm{~mL}$ aliquots as the glucose released by enzymatic hydrolysis after 20 and 120 min, respectively. The remaining mixture was heated in a boiling water bath, treated with $7 \mathrm{M} \mathrm{KOH}$, and hydrolyzed further with amyloglucosidase $(50 \mathrm{U} / \mathrm{mL})$ to determine TS. RS, which is the starch fraction that remained unhydrolyzed after $120 \mathrm{~min}$, was obtained by subtracting RDS and SDS from TS (RS $=$ TS - [RDS + SDS]) [1]. The amount of glucose released at a given period of hydrolysis was determined with a D-glucose oxidase-peroxidase assay kit (Megazyme, Wicklow, Ireland).

\subsection{Statistical analysis}

$\mathrm{JMP}^{\circledR}$ software version 7 (SAS Software Institute, Cary, NC, USA) was used in the chemometric analysis of the experimental data. The 16 samples from Arkansas and 16 samples from Texas consisted of the same set of cultivars but were considered as different data points due to the well known influence of growing environment on rice quality [22]. As a result, the total number of observations $(n)$ used in the analyses was 32 instead of 16 . Tukey's honestly significant difference (HSD) test was used to identify significantly different means between groups. Bivariate correlation was carried out by the Pearson-product moment approach. Principal component (PC) analysis was performed to obtain a simplified view of the relationship among samples, and between NISF and rice quality indices. A stepwise regression approach was employed in the multiple linear regression analysis, and cross-validation was chosen for the partial least squares (PLSs) regression analysis. Coefficients of determination $\left(R^{2}\right)$, correlation coefficients $(R)$, and root mean square errors (RMSEs) were used as indicators of significance for the regressions models.

\section{Results and discussion}

\subsection{Sample genotype and NISF}

Table 1 presents the grain type, $\mathrm{CT}_{n}$ and amylose class of the cultivars used in this study. The samples were associated with $5 \mathrm{CT}_{n}$ alleles of the Waxy microsatellite RM190 $\left(\mathrm{CT}_{11}, \mathrm{CT}_{14}, \mathrm{CT}_{17}, \mathrm{CT}_{18}\right.$, and $\left.\mathrm{CT}_{20}\right)$ and the number of samples $(n)$ belonging to each $\mathrm{CT}_{n}$ marker was as follows: $\mathrm{CT}_{11}=14, \mathrm{CT}_{14}=4, \mathrm{CT}_{17}=4, \mathrm{CT}_{18}=6$, and $\mathrm{CT}_{20}=4$. The $\mathrm{CT}_{n}$ microsatellite markers were also used in designating the amylose class of each cultivar as reported by previous workers [5-7]. $\mathrm{CT}_{11}$ and $\mathrm{CT}_{20}$ were associated with high $\mathrm{AM} ; \mathrm{CT}_{14}$ with intermediate $\mathrm{AM} ; \mathrm{CT}_{18}$ with low $A M$; and $\mathrm{CT}_{17}$ with low $\mathrm{AM}$ or waxy $(0-5 \% \mathrm{AM})$. The hybrid cultivar XP723 was actually associated with both $\mathrm{CT}_{14}$ and $\mathrm{CT}_{20}$ alleles but was included in the $\mathrm{CT}_{14}$ group because its AM content was intermediate (Table 2). Typical US cultivars having the $\mathrm{CT}_{20}$ allele are also intermediate-AM. However, the $\mathrm{CT}_{20}$ samples used in this study (Cheniere and Cocodrie) were high-AM type due to the presence of single nucleotide polymorphic (SNP) sites in exon 10 of the waxy gene [7, 8]. A more detailed report on the association of rice AM classes with microsatellite genetic markers has been described elsewhere [7]. Grain type was derived based on milled rice grain length/width ratio (data not shown). Eight samples were medium-grain type, while the remaining 24 were long-grain. Table 2 shows the cooked rice NISF of the samples grouped according to $\mathrm{CT}_{n}$ Considering the ranges on Table 2 and the NISF

Table 2. Ranges and means $\pm S D$ for cooked rice NISFs of rice samples group according to $\mathrm{CT}_{n}$ repeat $^{\mathrm{a})}$

\begin{tabular}{|c|c|c|c|c|c|c|c|}
\hline \multirow[t]{2}{*}{ Genetic marker group } & \multirow[t]{2}{*}{ Amylose class } & \multicolumn{2}{|c|}{ RDS (\%) } & \multicolumn{2}{|c|}{ SDS (\%) } & \multicolumn{2}{|c|}{ RS (\%) } \\
\hline & & Range & Mean \pm SD & Range & Mean \pm SD & Range & Mean \pm SD \\
\hline $\mathrm{CT}_{11}(n$ & High & $53.9-63.0$ & $59.9 \pm 2.5^{b}$ & $11.0-23.2$ & $18.2 \pm 4.1^{\mathrm{a}}$ & $3.7-7.9$ & $6.1 \pm 1.3^{\mathrm{a}}$ \\
\hline $\mathrm{CT}_{14}(n=4)$ & Intermediate & $58.3-64.0$ & $61.8 \pm 2.7^{\mathrm{ab}}$ & $12.4-16.3$ & $14.7 \pm 1.6^{b}$ & $3.2-5.1$ & $4.3 \pm 0.9^{b}$ \\
\hline $\mathrm{CT}_{17}(n=4)$ & Waxy/low & $60.0-67.6$ & $63.5 \pm 3.3^{a}$ & $15.7-19.8$ & $17.9 \pm 2.0^{a}$ & $2.2-6.0$ & $3.5 \pm 1.7^{\mathrm{bc}}$ \\
\hline $\mathrm{CT}_{18}(n=6)$ & Low & $56.1-65.6$ & $60.7 \pm 3.6^{\mathrm{ab}}$ & $12.8-24.2$ & $17.7 \pm 5.3^{a}$ & $1.2-3.9$ & $2.5 \pm 0.9^{c}$ \\
\hline $\mathrm{CT}_{20}(n=4)$ & High & $58.6-62.3$ & $60.3 \pm 1.5^{\mathrm{ab}}$ & $16.2-22.7$ & $18.8 \pm 3.2^{a}$ & $5.5-7.7$ & $6.4 \pm 1.0^{\mathrm{a}}$ \\
\hline
\end{tabular}

a) Means in a column with a common superscript letter(s) are not significantly different from one another based on Tukey's HSD test $(p>0.05)$. 


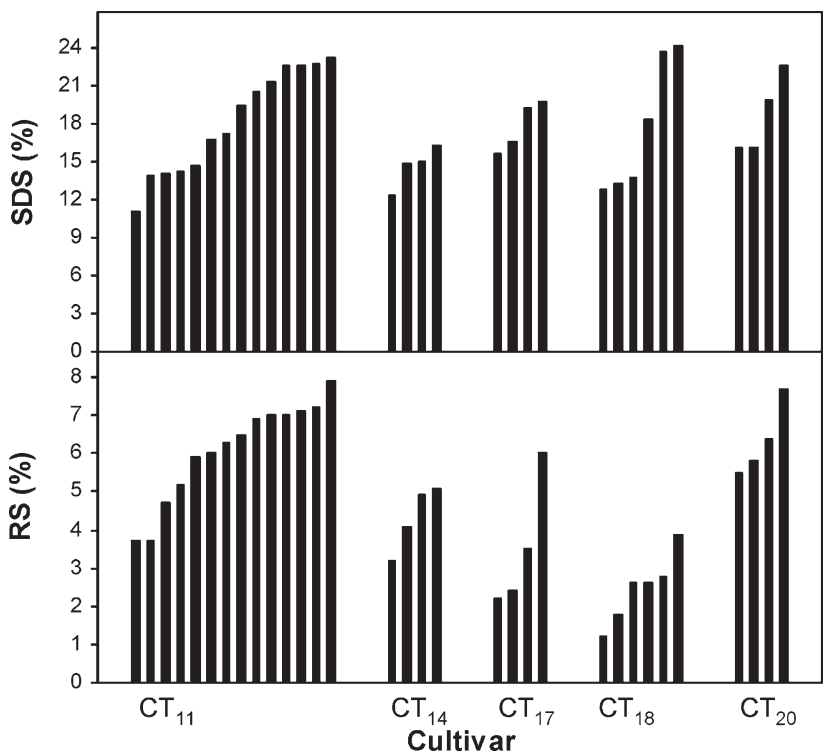

Figure 1. SDS and RS of the rice samples grouped according to $\mathrm{CT}_{n} \mathrm{~s}$. (The 32 data points represented 16 cultivars grown in 2 environments.)

profiles of the different samples in Fig. 1, overlapping occurred for RDS, SDS, and RS among $\mathrm{CT}_{n}$ groups and among samples in each group. Taking the means into account (despite unequal $n$ among $\mathrm{CT}_{n}$ groups), the $\mathrm{CT}_{11}$ samples (high-AM type) were generally associated with higher percentages of SDS and RS, and a lower RDS. The $\mathrm{CT}_{20}$ samples (also high-AM type) were comparable to the $\mathrm{CT}_{11}$ group in SDS and RS but their comparatively higher RDS was more similar to the other $\mathrm{CT}_{n}$ groups $\left(\mathrm{CT}_{14}, \mathrm{CT}_{17}\right.$, and $\left.\mathrm{CT}_{18}\right)$. The $\mathrm{CT}_{17}$ and $\mathrm{CT}_{18}$ samples (waxy to low-AM type) were generally characterized by a lower percentage of RS, but with SDS and RDS that were both comparable to the $\mathrm{CT}_{20}$ group. On the other hand, both RS and SDS of the $\mathrm{CT}_{14}$ samples (intermediateamylose type) tended to be lower.

\subsection{Bivariate correlations}

Tables 3-5 list the ranges and means of the basic grain quality indices, pasting characteristics, and thermal properties, respectively, of the different rice samples grouped according to $\mathrm{CT}_{n} \mathrm{AM}$ widely varied from 0 to $32.6 \%$ and the values were in total agreement with the amylose class based on $\mathrm{CT}_{n}$ marker (Table 3). The AM range among $\mathrm{CT}_{n}$ groups did not overlap contrary to the other physicochemical properties. CP ranged from 6.6 to $10.4 \%$, but on average was not different for all the $\mathrm{CT}_{n}$ groups. On average, the AS of the $5 \mathrm{CT}_{n}$ groups did not differ as well. As to the GC, the noticeable difference was between $\mathrm{CT}_{14}$ and $\mathrm{CT}_{20}$ groups, in which it was higher for the latter (Table 3). For pasting properties (Table 4), it is interesting to note that the high-amylose $\mathrm{CT}_{n}$ groups $\left(\mathrm{CT}_{11}\right.$ and $\left.\mathrm{CT}_{20}\right)$ were differentiated from each other by lower PV, FV, SB, and TSB of the latter. Furthermore, the waxy to low amylose groups $\left(\mathrm{CT}_{17}\right.$ and $\left.\mathrm{CT}_{18}\right)$ were differentiated by the lower $\mathrm{PV}$ of the former (Table 4). A more detailed report on the association of rice pasting properties with microsatellite genetic markers has been described elsewhere [8]. In terms of thermal properties, the OT, PT, GR, and GE of the samples in the $\mathrm{CT}_{18}$ group were noticeably lower compared to the $\mathrm{CT}_{20}$ group; whereas, those of $\mathrm{CT}_{11}, \mathrm{CT}_{14}$, and $\mathrm{CT}_{17}$ group were either similar to $\mathrm{CT}_{18}$ or $\mathrm{CT}_{20}$ (Table 5). It is well known that low-amylose cultivars, such as those in the $\mathrm{CT}_{18}$ group, tend to gelatinize at lower temperatures, although cultivars of similar amylose content may differ in thermal properties due to differences in amylopectin fine structure [23, 24].

Bivariate correlations between NISF and the 16 variables (AM, AS, BD, CP, FV, GC, GE, GR, OT, PV, PT, RDS, RS, SB, SDS, and TSB) given in Tables 3-5 are presented in Table 6. RS was positively correlated with AM, FV, SB, TSB, and PT (peak gelatinization temperature). RS also a showed significant inverse relationship with BD. The positive linear correlation between RS and AM has been reported in previous works [4, 9-14]. On the other hand,

Table 3. Ranges and means $\pm S D$ for the basic grain quality indices of rice samples grouped according to $\mathrm{CT}_{n}$ repeat ${ }^{\mathrm{a})}$

\begin{tabular}{|c|c|c|c|c|c|c|c|c|}
\hline \multirow[t]{2}{*}{ Genetic marker group } & \multicolumn{2}{|c|}{ AM (\%) } & \multicolumn{2}{|c|}{ CP (\%) } & \multicolumn{2}{|r|}{ AS } & \multicolumn{2}{|c|}{$\mathrm{GC}(\mathrm{mm})$} \\
\hline & Range & Mean $\pm S D$ & Range & Mean \pm SD & Range & Mean \pm SD & Range & Mean $\pm S D$ \\
\hline $\mathrm{CT}_{11}(n=14)$ & $26.4-32.6$ & $29.2 \pm 2.0^{\mathrm{a}}$ & $6.6-10.3$ & $8.3 \pm 1.0^{\mathrm{a}}$ & $4.0-7.0$ & $4.9 \pm 1.3^{\mathrm{a}}$ & $14.0-73.5$ & $41.4 \pm 27.0^{\mathrm{ab}}$ \\
\hline $\mathrm{CT}_{14}(n=4)$ & $19.6-22.7$ & $21.3 \pm 1.3^{b}$ & $7.2-9.3$ & $8.2 \pm 1.0^{a}$ & $3.1-4.0$ & $3.5 \pm 0.4^{a}$ & $14.5-34.5$ & $24.2 \pm 8.4^{b}$ \\
\hline $\mathrm{CT}_{17}(n=4)$ & $0.0-12.8$ & $6.3 \pm 6.7^{d}$ & $6.7-9.1$ & $7.9 \pm 1.1^{a}$ & $2.5-6.0$ & $4.4 \pm 1.9^{a}$ & $37.0-50.5$ & $46.1 \pm 6.2^{\mathrm{ab}}$ \\
\hline $\mathrm{CT}_{18}(n=6)$ & $7.9-11.7$ & $10.0 \pm 1.5^{\mathrm{c}}$ & $7.3-10.4$ & $8.8 \pm 1.2^{a}$ & $2.0-6.0$ & $4.7 \pm 2.0^{\mathrm{a}}$ & $28.5-72.5$ & $46.2 \pm 16.8^{\mathrm{ab}}$ \\
\hline $\mathrm{CT}_{20}(n=4)$ & $28.4-31.8$ & $29.9 \pm 1.7^{a}$ & $7.2-9.3$ & $8.3 \pm 1.0^{a}$ & $3.6-4.0$ & $3.9 \pm 0.2^{\mathrm{a}}$ & $37.0-74.5$ & $57.0 \pm 16.9^{a}$ \\
\hline
\end{tabular}

a) Means in a column with a common superscript letter(s) are not significantly different from one another based on Tukey's HSD test $(p>0.05)$. 
Table 4. Ranges and means $\pm \mathrm{SD}$ for the pasting properties of head rice samples grouped according to $\mathrm{CT}_{n}$ repeat ${ }^{\mathrm{a})}$

\begin{tabular}{|c|c|c|c|c|c|c|c|c|c|c|}
\hline \multirow{2}{*}{$\begin{array}{l}\text { Genetic } \\
\text { marker } \\
\text { group }\end{array}$} & \multicolumn{2}{|c|}{ PV (RVU) } & \multicolumn{2}{|c|}{$\mathrm{FV}$ (RVU) } & \multicolumn{2}{|c|}{ BD (RVU) } & \multicolumn{2}{|c|}{ SB (RVU) } & \multicolumn{2}{|c|}{ TSB (RVU) } \\
\hline & Range & Mean \pm SD & Range & Mean \pm SD & Range & Mean \pm SD & Range & Mean \pm SD & Range & Mean \pm SD \\
\hline $\begin{array}{l}\mathrm{CT}_{11} \\
(n=14)\end{array}$ & $258-348$ & $295 \pm 25^{\mathrm{ab}}$ & $321-542$ & $383 \pm 53^{a}$ & $53-113$ & $96 \pm 20^{b c}$ & $43-194$ & $88 \pm 35^{a}$ & $120-280$ & $184 \pm 39^{a}$ \\
\hline $\begin{array}{l}\mathrm{CT}_{14} \\
(n=4)\end{array}$ & $279-318$ & $294 \pm 18^{a b}$ & $266-307$ & $284 \pm 18^{b}$ & $124-171$ & $142 \pm 20^{\mathrm{a}}$ & $-43-8$ & $-11 \pm 24^{c}$ & $123-142$ & $131 \pm 8^{b}$ \\
\hline $\begin{array}{l}\mathrm{CT}_{17} \\
(n=4)\end{array}$ & 228-298 & $264 \pm 31^{b}$ & 150-249 & $200 \pm 49^{c}$ & $118-130$ & $125 \pm 6^{\mathrm{ab}}$ & $-83--42$ & $-63 \pm 20^{d}$ & $38-88$ & $61 \pm 26^{c}$ \\
\hline $\begin{array}{l}\mathrm{CT}_{18} \\
(n=6)\end{array}$ & $240-356$ & $307 \pm 40^{a}$ & 213-295 & $242 \pm 31^{\mathrm{bc}}$ & 76-203 & $148 \pm 49^{a}$ & $-121-14$ & $-65 \pm 54^{d}$ & $74-93$ & $82 \pm 8^{c}$ \\
\hline $\begin{array}{l}\mathrm{CT}_{20} \\
(n=4)\end{array}$ & $162-211$ & $188 \pm 20^{c}$ & $190-261$ & $230 \pm 37^{b c}$ & $74-94$ & $85 \pm 9^{c}$ & $23-68$ & $42 \pm 21^{b}$ & $110-142$ & $127 \pm 16^{b}$ \\
\hline
\end{tabular}

a) Means in a column with a common superscript letter(s) are not significantly different from one another based on Tukey's HSD test $(p>0.05)$.

Table 5. Ranges and means $\pm S D$ for the thermal properties of head rice samples grouped according to $\mathrm{CT}_{n}$ repeat ${ }^{\mathrm{a})}$

\begin{tabular}{|c|c|c|c|c|c|c|c|c|}
\hline \multirow{2}{*}{$\begin{array}{l}\text { Genetic } \\
\text { marker group }\end{array}$} & \multicolumn{2}{|c|}{ Onset GT $\left({ }^{\circ} \mathrm{C}\right)$} & \multicolumn{2}{|c|}{ Peak GT $\left({ }^{\circ} \mathrm{C}\right)$} & \multicolumn{2}{|c|}{$\mathrm{GR}\left({ }^{\circ} \mathrm{C}\right)$} & \multicolumn{2}{|c|}{ GE (J/g) } \\
\hline & Range & $S D$ & ge & & & D & ange & SD \\
\hline & & & & & & & & \\
\hline$=4)$ & $82.1-87.3$ & $85.7 \pm 2.4^{a b}$ & $104.0-108.9$ & $106.3 \pm 2.1^{\mathrm{ab}}$ & $42.0-44.3$ & $43.0 \pm 1.0^{a}$ & $10.5-12.3$ & $11.5 \pm 0.9^{\mathrm{ab}}$ \\
\hline$=4)$ & $81.8-87.2$ & $84.2 \pm 2.5^{b}$ & $97.6-104.8$ & $101.8 \pm 3.4^{b c}$ & $38.4-43.8$ & $41.7 \pm 2.5^{\mathrm{ab}}$ & $3.9-14.5$ & $9.3 \pm 5.2^{\mathrm{ab}}$ \\
\hline$=6)$ & $82.1-87.2$ & 84.5 & $92.8-106.8$ & $99.9 \pm 4.8^{c}$ & $30.8-41.7$ & $39.0 \pm 4.1^{b}$ & $4.2-12.0$ & $8.2 \pm 3.5^{b}$ \\
\hline$=4)$ & $86.9-88.8$ & $87.6 \pm 0.9^{a}$ & $107.1-108.2$ & $107.5 \pm 0.5^{a}$ & $37.4-45.1$ & $41.1 \pm 4.0^{\mathrm{ab}}$ & $9.8-13.1$ & $11.9 \pm 1.4^{\mathrm{a}}$ \\
\hline
\end{tabular}

a) Means in a column with a common superscript letter(s) are not significantly different from one another based on Tukey's HSD test $(p>0.05)$.

Table 6. Bivariate correlation matrix ${ }^{a), b)}$

\begin{tabular}{lccc}
\hline Property & RDS & SDS & RS \\
\hline Basic quality indices & & & $0.788^{* * *}$ \\
AM & $-0.312^{\mathrm{ns}}$ & $0.106^{\mathrm{ns}}$ & $0.024^{\mathrm{ns}}$ \\
Total protein & $0.188^{\mathrm{ns}}$ & $-0.347^{\mathrm{ns}}$ & $0.144^{\mathrm{ns}}$ \\
AS & $0.054^{\mathrm{ns}}$ & $-0.227^{\mathrm{ns}}$ & $0.241^{\mathrm{ns}}$ \\
GC & $-0.019^{\mathrm{ns}}$ & $0.459^{*}$ & $0.233^{\mathrm{ns}}$ \\
Thermal properties & & & $0.395^{*}$ \\
Onset GT & $-0.145^{\mathrm{ns}}$ & $0.134^{\mathrm{ns}}$ & $0.096^{\mathrm{ns}}$ \\
Peak GT & $-0.132^{\mathrm{ns}}$ & $0.115^{\mathrm{ns}}$ & $-0.032^{\mathrm{ns}}$ \\
GR & $-0.277^{\mathrm{ns}}$ & $0.164^{\mathrm{ns}}$ & $-0.284^{\mathrm{ns}}$ \\
GE & $-0.016^{\mathrm{ns}}$ & $0.155^{\mathrm{ns}}$ & $0.501^{* *}$ \\
Pasting properties & & & $-0.526^{* *}$ \\
PV & $-0.061^{\mathrm{ns}}$ & $-0.083^{\mathrm{ns}}$ & $0.744^{* * *}$ \\
FV & $-0.124^{\mathrm{ns}}$ & $-0.196^{\mathrm{ns}}$ & $0.687^{* * *}$ \\
BD viscosity & $0.130^{\mathrm{ns}}$ & $0.087^{\mathrm{ns}}$ & $-0.174^{\mathrm{ns}}$ \\
SB viscosity & $-0.111^{\mathrm{ns}}$ & $-0.183^{\mathrm{ns}}$ & \\
TSB & $-0.070^{\mathrm{ns}}$ & & \\
\hline
\end{tabular}

a) Statistical significance: ${ }^{*} p \leq 0.05 ;{ }^{* *} p \leq 0.01 ;{ }^{* * *} p \leq 0.001$; ns not significant, $p>0.05$.

b) RDS, rapidly digestible starch; SDS, slowly digestible starch; RS, resistant starch. 
Benmoussa et al. [16] reported a significant positive correlation between RDS and $\mathrm{BD}$ and a negative correlation between SDS and BD but such associations were not observed in this work. It should be pointed out that Benmoussa et al. [16] used rice starch samples in assaying NISF and pasting characteristics; whereas, in this work whole grains were used in the NISF assays and rice flour for the viscosity and pasting tests. RDS did not show significant correlations with any of the physicochemical variables, whereas, SDS was significantly correlated only with GC. The lack of significant correlations between these physicochemical variables with RDS and SDS imply that these variables are not useful by themselves for predicting RDS or SDS.

\subsection{Principal component analysis}

PC analysis was carried out to show the interrelationships among the rice samples and physicochemical variables in a visually intuitive manner [17]. A total of 14 PCs completely explained the variance of the 16-variable dataset. The first five PCs (PC1-5) had Eigen values $\geq 1$ and accounted for $83.3 \%$ of the data variation. PC1 and PC2, with respective Eigen values of 4.8 and 3.8 , accounted for 30.2 and $23.8 \%$ of the variation, respectively. A similarity map based on score and loading plots for PC1 and PC2 is shown in Fig. 2. The score plot (Fig. 2A) shows that the $\mathrm{CT}_{11}$ and $\mathrm{CT}_{20}$ samples were mainly positioned on the first $(+x,+y)$ and fourth quadrants $(+x,-y)$ of the similarity map, whereas, the $\mathrm{CT}_{14}, \mathrm{CT}_{17}$, and $\mathrm{CT}_{18}$ were distributed on the second $(-x,+y)$ and third quadrants $(-x,-y)$. Hence, the sit-together rule of PCs analysis points to the close resemblance in physicochemical properties among $\mathrm{CT}_{11}$ and $\mathrm{CT}_{20}$ samples, and among $\mathrm{CT}_{14}$, $\mathrm{CT}_{17}$, and $\mathrm{CT}_{18}$ samples. Considering the samples within a $\mathrm{CT}_{n}$ group, those with the $\mathrm{CT}_{20}$ marker appeared to be more related in properties than the samples from other groups as they were loaded more close to each other on the similarity map. The three NISF variables were positioned on three different quadrants as follows: RS on the first, SDS on the second, and RDS on the third (Fig. 2B). $\mathrm{RS}$ and RDS were loaded on opposite quadrants indicating that these two variables are inversely related. SDS had some direct association with RS owing to their common $>0$ PC2 load. In addition, SDS was directly associated with RDS to some extent due to their common $<0$ PC1 load.

RS was loaded on the first quadrant together with AM, TSB, SB, OT, and PT and by the sit-together rule, these variables are closely associated. Such associations nearly matched those obtained with bivariate correlation analysis in which RS significantly correlated with AM, FV, SB, TSB, and PT (Table 6). On the other hand, SDS was loaded on the second quadrant along with GC, GR, and GE. This association is somewhat different from that obtained with
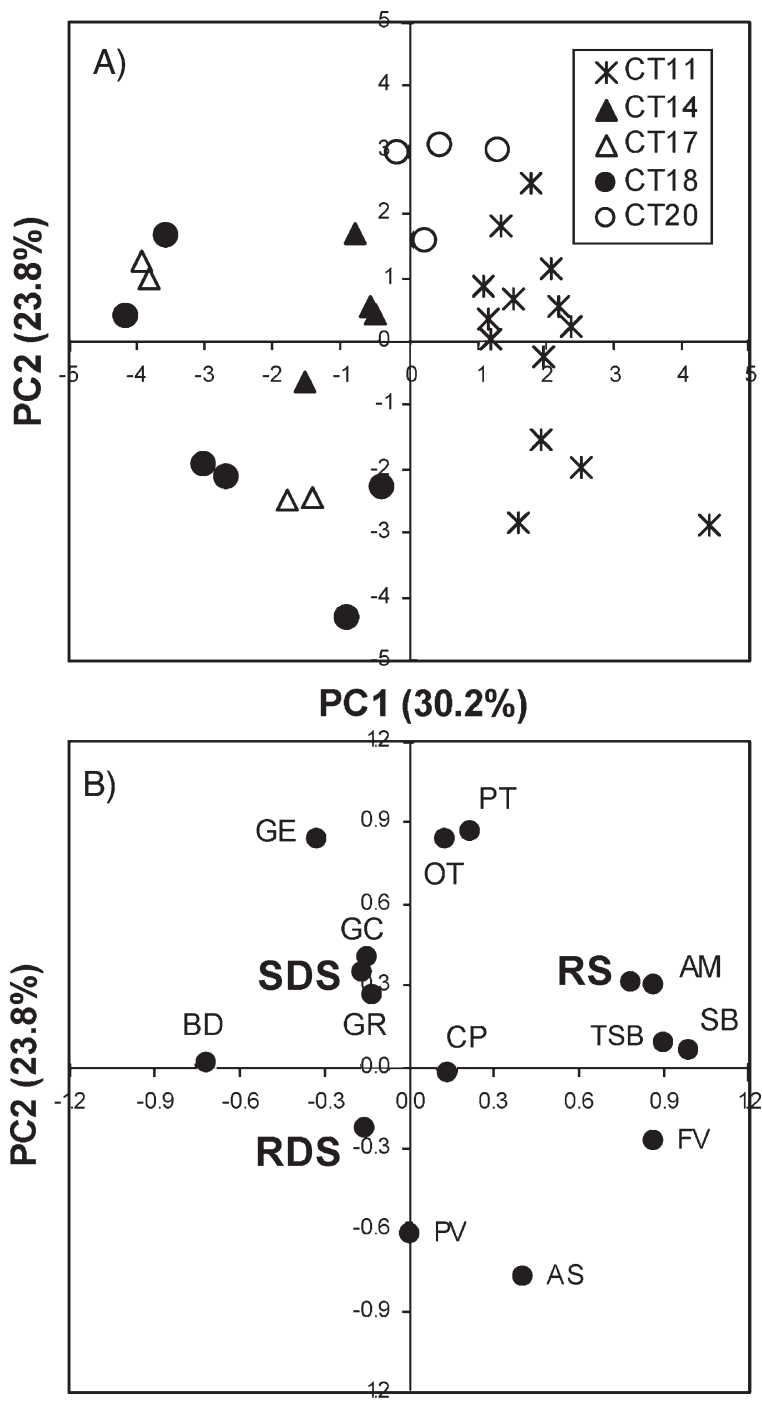

PC1 (30.2\%)

Figure 2. A similarity map based on score $(A)$ and variable (B) loadings of the first (PC1) and second components (PC2) derived by $\mathrm{PC}$ analysis.

bivariate correlation analysis in which SDS was significantly correlated with GC only. PV, FV, and AS were scattered on the fourth quadrant and positioned opposite SDS to indicate their inverse relationship. RDS was positioned on the third quadrant all by itself to imply that its direct association with other physicochemical properties was weak. It should be recalled that RDS did not show significant correlation with any of the physicochemical variables when bivariate correlation analysis was used (Table 6). PC analysis is not a quantitative modeling tool so that other multivariate techniques are necessary to further verify the relation of the different physicochemical variables with NISF. 
Table 7. Multiple linear regression matrix ${ }^{a), b)}$

\begin{tabular}{|c|c|c|c|c|c|c|}
\hline $\begin{array}{l}\text { Number of } \\
\text { variables }\end{array}$ & a) Predictor and regression coefficient & Intercept & $R^{2}$ & $R$ & RMSE & Prob $>F$ \\
\hline \multicolumn{7}{|l|}{ RDS } \\
\hline 1 & AM $(-0.090)$ & 62.77 & $0.10^{\text {ns }}$ & 0.32 & 2.76 & 0.0818 \\
\hline 2 & AM (-0.195), TSB (0.024) & 61.84 & $0.18^{\mathrm{ns}}$ & 0.42 & 2.68 & 0.0585 \\
\hline 3 & $\mathrm{AM}(-.0271), \mathrm{PV}(-0.021), \mathrm{TSB}(0.038)$ & 67.53 & $0.26^{*}$ & 0.51 & 2.59 & 0.0345 \\
\hline 4 & $\begin{array}{l}\text { AM }(-0.262), \text { GR }(-0.177) \\
\text { PV }(-0.023), \text { TSB }(0.037)\end{array}$ & 75.02 & $0.33^{*}$ & 0.57 & 2.52 & 0.0260 \\
\hline 5 & $\begin{array}{l}\text { AM }(-0.231), \text { AS }(0.813), \mathrm{FV}(-0.043) \\
\text { GR }(-0.198), \text { TSB }(0.086)\end{array}$ & 71.59 & $0.40^{*}$ & 0.63 & 2.41 & 0.0147 \\
\hline $\begin{array}{l}13 \\
\text { SDS }\end{array}$ & All variables & 66.09 & $0.49^{\text {ns }}$ & 0.70 & 2.53 & 0.1261 \\
\hline 1 & $\mathrm{GC}(0.081)$ & 14.19 & $0.21^{* *}$ & 0.46 & 3.45 & 0.0083 \\
\hline 2 & $\mathrm{GC}(0.073), \mathrm{CP}(-1.026)$ & 23.08 & $0.28^{* *}$ & 0.53 & 3.34 & 0.0079 \\
\hline 3 & AM (0.216), GC (0.070), TSB (-0.041) & 15.48 & $0.35^{* *}$ & 0.59 & 3.24 & 0.0066 \\
\hline 4 & AM (0.309), GC (0.082), PV (0.027), TSB (-0.058) & 7.55 & $0.42^{* *}$ & 0.65 & 3.11 & 0.0039 \\
\hline 5 & $\begin{array}{l}\mathrm{AM}(0.274), \mathrm{AS}(-1.454), \mathrm{FV}(0.063) \\
\mathrm{GC}(0.105), \mathrm{TSB}(-1.130)\end{array}$ & 12.24 & $0.53^{* * *}$ & 0.73 & 2.85 & 0.0008 \\
\hline $\begin{array}{l}13 \\
\mathrm{RS}\end{array}$ & All variables & 73.12 & $0.62^{*}$ & 0.79 & 2.93 & 0.0170 \\
\hline 1 & AM (0.152) & 1.58 & $0.62^{* * *}$ & 0.79 & 1.19 & $<0.0001$ \\
\hline 2 & AM (0.150), GC (0.019) & 0.78 & $0.67^{* * *}$ & 0.82 & 1.14 & $<0.0001$ \\
\hline 3 & AM (0.079), GC (0.026), SB (0.011) & 1.81 & $0.72^{* * *}$ & 0.85 & 1.05 & $<0.0001$ \\
\hline 4 & AM (0.074), GC (0.022), PV (-0.006), SB (0.011) & 3.62 & $0.74^{* * *}$ & 0.86 & 1.04 & $<0.0001$ \\
\hline 5 & $\begin{array}{l}\text { AM (0.077), GC (0.018), OT }(-0.217) \text {, } \\
\text { PV }(-0.016), \text { TSB }(0.017)\end{array}$ & 23.23 & $0.77^{* * *}$ & 0.88 & 1.01 & $<0.0001$ \\
\hline 13 & All variables & 26.27 & $0.77^{* * *}$ & 0.88 & 1.13 & 0.0002 \\
\hline
\end{tabular}

a) Statistical significance: ${ }^{*} p \leq 0.05 ;{ }^{* *} p \leq 0.01 ;{ }^{* * *} p \leq 0.001$; ns not significant, $p>0.05$.

b) AM, apparent amylose; AS, alkali spreading value; CP, crude protein; FV, final viscosity; GC, gel consistency; GR, gelatinization range; OT, onset gelatinization temperature; $\mathrm{PV}$, peak viscosity; SB, setback viscosity; and TSB, total setback viscosity; $R^{2}$ coefficient of determination; $R$, regression coefficient; RMSE, root mean square error.

\subsection{Multiple linear regression}

Stepwise multiple linear regression analysis was used to create models for each NISF (as response variable) regressed against 13 predictor variables. Only the bestfit regression models, with 1-5 predictor variables that gave the highest $R^{2}$ and lowest RMSE are presented in Table 7. As proposed by several statisticians, the number of predictor variables to consider in generating multiple linear regression models should not be more than $1 / 5$ of the total number of observations ( $n=32$ in this work) in order to minimize the possibility of chance correlations [25]. The best-fit models shown in Table 7 explained $10-77 \% \quad\left(R^{2}=0.10-0.77\right)$ of the variation in NISF (RDS, SDS, and RS) among the 32 data points. The models for predicting RDS showed a relatively low $R^{2}$ (0.1-0.5) and a high RMSE (2.4-2.8). In fact, only three models that consisted of 3-5 predictor variables were significant at $p \leq 0.5$. It was observed that both $A M$ and TSB were common to the three models; AS, GR, FV, and $P V$ were also included but with a lower frequency. The selected models for predicting SDS were all significant, with AM, GC, and TSB as the common variables. The other variables included in the model but to a lower frequency were AS, CP, FV, and PV. Higher $R^{2}(0.6-0.8)$ and lower RMSE (1.0-1.2) were obtained in the models for predicting $\mathrm{RS}$, with $\mathrm{AM}$ and $\mathrm{GC}$ as the common variables. Overall, the results of the multiple linear regression analysis implicate the importance of $\mathrm{AM}, \mathrm{GC}$, and TSB in predicting NISF.

\subsection{Partial least squares regression}

PLSs regression is typically used when the independent variables are correlated, or the number of the independent variables exceeds the number of observations. PLS regression differs from standard multiple linear regression 
as it accounts the variation of both response and predictor variables [17]. Bivariate correlation analysis showed that collinearity tended to exist among pasting variables ( $\mathrm{PV}$, $\mathrm{FV}, \mathrm{BD}, \mathrm{SB}$, and TSB) as these variables were all derived from the same pasting profile/curve measured by a single instrument, the RVA (data not shown). The same is true for the thermal variables (GE, GR, OT, and PT), which were all determined with a multi-cell differential scanning calorimeter. Hence, PLS regression analysis appeared to be more appropriate to use in modeling NISF (as response variable) with pasting and thermal properties (as predictors). The PLS regression models were derived by regressing the 13 predictor variables in groups as follows: basic quality indices (AM, AS, CP, and GC), pasting properties (BD, FV, PV, SB, and TSB), and thermal properties (GE, $\mathrm{GR}, \mathrm{OT}$, and PT). Deriving the models involved the extraction of minimum number of latent vectors that gave the lowest prediction RMSE upon cross-validation. A summary of the coefficients and other important parameters obtained from PLS regression analysis is shown in Table 8. Figures 3 and 4 show the plots for actual and predicted SDS and RS, respectively, using the PLS regression models. The prediction models for RDS generally lacked robustness, explaining only $2-12 \%\left(R^{2}=0.02-0.12\right)$ of the variation of the response variable. The models were also characterized by high prediction RMSE (1.09-1.15). Even then, the predictor variables that comprised the basic quality indices group turned out as a better predictor for
RDS compared with the pasting and thermal property groups. For SDS, the models explained 4-31\% $\left(R^{2}=0.04-0.31\right)$ of its variation, and only the model derived with the basic grain quality indices as predictors was noteworthy (Fig. 3). On the other hand, RS was adequately predicted by the basic quality indices, pasting, and thermal properties, with $38-75 \%\left(R^{2}=0.30-0.75\right)$ of its variation explained (Fig. 4). Among the three groups of predictor variables, the basic quality indices also appeared as better predictors for RS.

\section{Conclusions}

Chemometrics elucidated the relationship of NISF with other rice physicochemical properties. $\mathrm{CT}_{11}$ was associated with higher amount of RS and SDS, and lower amount of RDS; $\mathrm{CT}_{14}$ was associated with low SDS; and $\mathrm{CT}_{17}$ and $\mathrm{CT}_{18}$ with low RS. The $\mathrm{CT}_{20}$ cultivars were similar to $\mathrm{CT}_{11}$ in SDS and RS contents, and to $\mathrm{CT}_{14}, \mathrm{CT}_{17}$, and $\mathrm{CT}_{18}$ with respect to RDS. PC analysis provided a simplified view of the interrelationship among samples, among variables, and between samples and variables. Bivariate correlation showed that RDS had no significant correlation with any of the physicochemical properties; whereas, SDS correlated positively with GC. RS correlated positively with $A M, S B$, TSB, and PT; and negatively with BD. Except GC, no single predictor variable could decently estimate SDS and RDS.

Table 8. PLSs regression matrix ${ }^{a)}$

\begin{tabular}{|c|c|c|c|c|c|c|}
\hline $\begin{array}{l}\text { Response } \\
\text { variable }\end{array}$ & Predictor variable and coefficient & Intercept & $\begin{array}{l}\text { Latent } \\
\text { vectors }\end{array}$ & $R^{2}$ & $R$ & $\overline{\mathrm{RMSE}}$ \\
\hline RDS & AM (-0.082), AS (0.100), CP (0.479), GC (-0.002) & 58.26 & 1 & 0.12 & 0.35 & 1.09 \\
\hline RDS & $\begin{array}{l}\text { BD }(0.004), \text { FV }(-0.002), P V(-0.001) \\
\text { SB }(-0.001), \text { TSB }(-0.001)\end{array}$ & 61.42 & 1 & 0.02 & 0.14 & 1.09 \\
\hline RDS & $\begin{array}{l}\text { GE }(-0.010), \text { GR }(-0.137), \text { OT }(-0.134) \text {, } \\
\text { PT }(-0.057)\end{array}$ & 83.86 & 1 & 0.05 & 0.22 & 1.08 \\
\hline RDS & All 13 variables & 76.28 & 1 & 0.12 & 0.35 & 1.15 \\
\hline SDS & AM (0.032), AS (-0.483), CP (-1.008), GC (0.063) & 24.82 & 1 & 0.31 & 0.56 & 0.95 \\
\hline SDS & $\begin{array}{l}\text { BD }(0.003), F V(-0.003), P V(-0.002) \\
\text { SB }(-0.003), \text { TSB }(-0.004)\end{array}$ & 19.42 & 1 & 0.04 & 0.20 & 1.06 \\
\hline SDS & GE (0.087), GR (0.065), OT (0.114), PT (0.046) & -0.26 & 1 & 0.04 & 0.20 & 1.05 \\
\hline SDS & All 13 variables & 7.33 & 1 & 0.23 & 0.48 & 1.04 \\
\hline RS & AM (0.147), AS (0.191), CP (0.043), GC (0.021) & -0.41 & 1 & 0.68 & 0.82 & 0.66 \\
\hline RS & $\begin{array}{l}\text { BD }(0.004), \text { FV }(0.001), \text { PV }(-0.018) \\
\text { SB }(0.009), \text { TSB }(0.016)\end{array}$ & 6.58 & 3 & 0.66 & 0.81 & 0.72 \\
\hline RS & GE (-0.442), GR (-0.045), OT (0.059), PT (0.412) & -37.21 & 3 & 0.38 & 0.62 & 0.89 \\
\hline RS & All 13 variables & 2.26 & 3 & 0.75 & 0.87 & 0.63 \\
\hline
\end{tabular}

a) AM, apparent amylose; AS, alkali spreading value; BD, breakdown viscosity; CP, crude protein; FV, final viscosity; GC, gel consistency; GE, gelatinization enthalpy; GR, gelatinization range; OT, onset gelatinization temperature; $P V$, peak viscosity; PT, peak gelatinization temperature; RDS, rapidly digestible starch; RS, resistant starch; SB, setback viscosity; SDS, slowly digestible starch; TSB, total setback viscosity; $R^{2}$ coefficient of determination; $R$, regression coefficient; RMSE, root mean square error. 


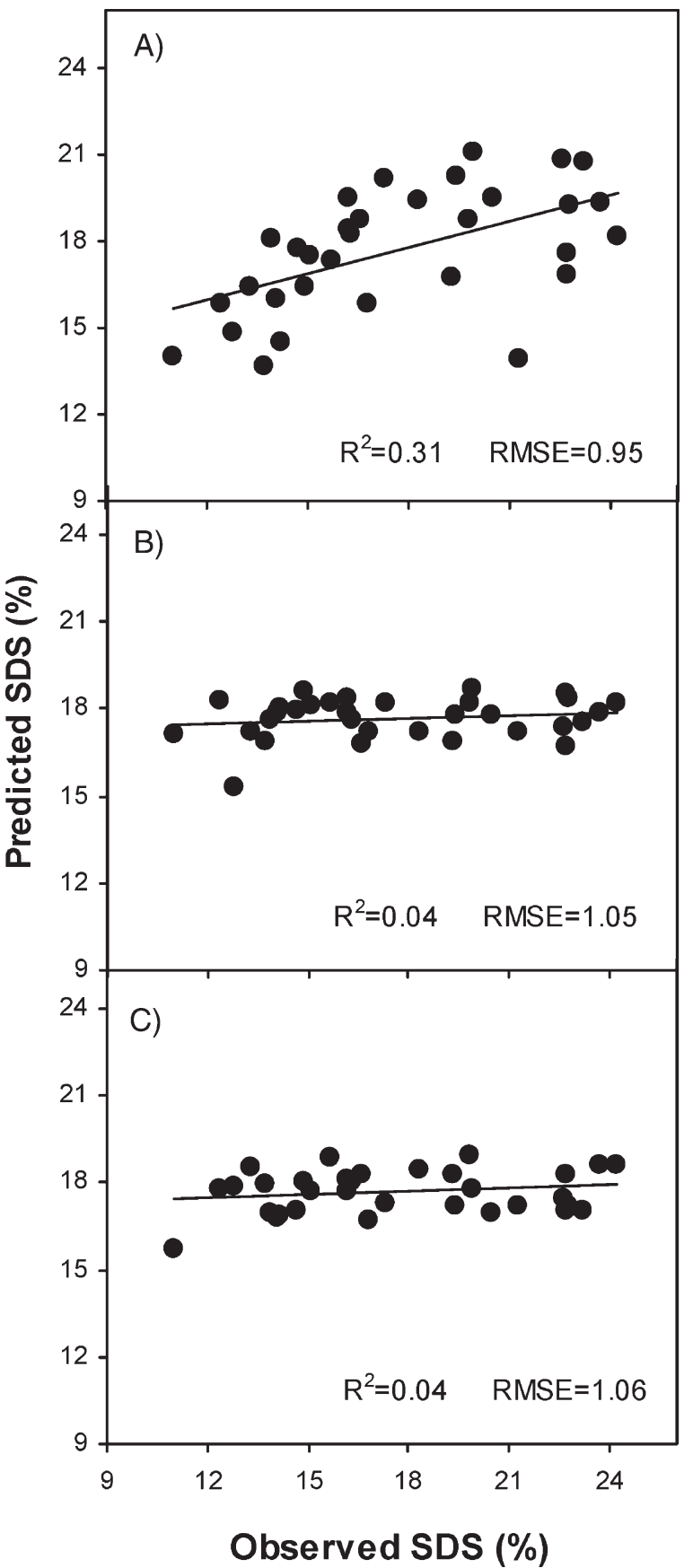

Figure 3. Actual and predicted SDS by PLS regression models with basic quality indices $(A)$, thermal properties (B), and pasting properties (C) as predictor variables.

Moreover, multivariate techniques (multiple linear regression and PLSs regression) indicated that $\mathrm{RS}$ was better predicted by the measured variables than SDS and RDS. Regression models for RDS and SDS generally lacked robustness, were characterized by low $R^{2}$ and high prediction RMSE, and explained less than $50 \%$ of the

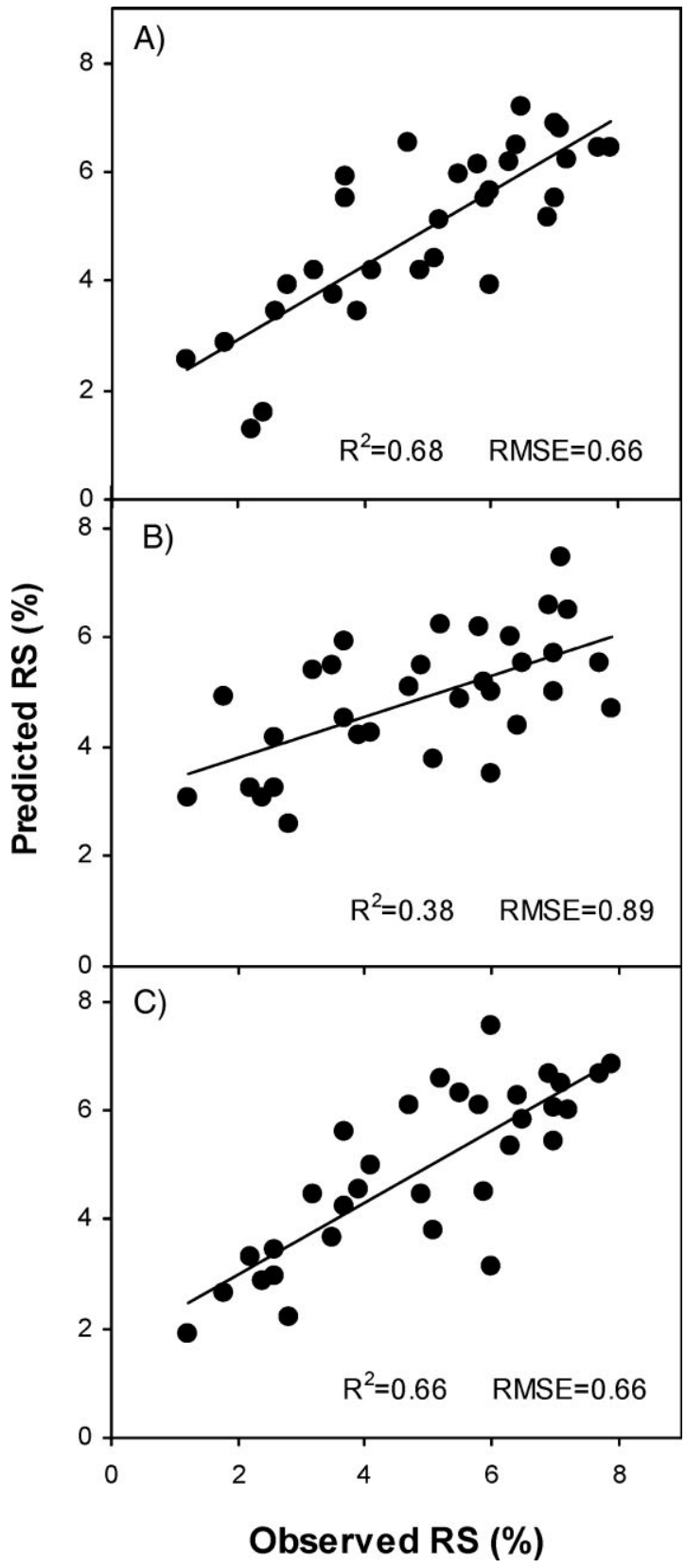

Figure 4. Actual and predicted RS by PLS regression models with basic quality indices (A), thermal properties $(B)$, and pasting properties (C) as predictor variables.

response variable's variation. In contrast, regression models for RS explained $62-77 \%$ of its variance. Variables that comprised the basic quality indices were better estimators of cooked rice NISF than pasting or thermal properties. It appears that starch properties other than those included in this study may better predict SDS and RDS. 
The authors thank Janis Delgado, Naomi Gipson, and Kim Daigle for their assistance in the grain quality tests; Eric Christensen for the microsatellite marker analysis; and James Gibbons, Karen Moldenhauer, and Steve Linscombe for producing the milled URRN rice samples.

The authors have declared no conflict of interest.

\section{References}

[1] Englyst, H. N., Kingman, S. M., Cummings, J. H., Classification and measurement of nutritionally important starch fractions. Eur. J. Clin. Nutr. 1992, 46, S33-S50.

[2] Lehmann, U., Robin, F., Slowly digestible starch-its structure and health implications: A review. Trends Food Sci. Technol. 2007, 18, 346-355.

[3] Sajilata, M. G., Singhal, R. S., Kulkarni, P. R., Resistant starch - a review. Comp. Rev. Food Sci. Food Safety 2006, 5, 1-17.

[4] Juliano, B. O., Structure, chemistry, and function of the rice grain and its fractions. Cereal Foods World 1992, 37, 77727779 .

[5] Ayres, N. M., McClung, A. M., Larkin, P. D., Bligh, H. F. J. et al., Microsatellites and a single-nucleotide polymorphism differentiate apparent amylose classes in an extended pedigree of US rice germplasm. Theor. Appl. Genet. 1997, 94, 773-781.

[6] Bergman, C. J., Delgado, J. T., McClung, A. M., Fjellstrom, R. G., An improved method for using a microsatellite in the rice waxy gene to determine amylose class. Cereal Chem. 2001, 78, 257-260.

[7] Chen, M. H., Bergman, C. J., Pinson, S. R. M., Fjellstrom, R. G., Waxy gene haplotypes: Associations with apparent amylose content and the effect by the environment in an international rice germplasm collection. J. Cereal Sci. 2008, 47, 536-545.

[8] Chen, M. H., Bergman, C. J., Pinson, S. R. M., Fjellstrom, R. G., Waxy gene haplotypes: Associations with pasting properties in an international rice germplasm collection. J. Cereal Sci. 2008, 48, 781-788.

[9] Eggum, B. O., Juliano, B. O., Perez, C. M., Acedo, E. F., The resistant starch, undigestible energy and undigestible protein contents of raw and cooked milled rice. J. Cereal Sci. 1993, $18,159-170$.

[10] Tetens, I., Biswas, S. K., Glitso, L. V., Kabir, K. A. et al., Physicochemical characteristics as indicators of starch availability from milled rice. J. Cereal Sci. 1997, 26, 355-361.

[11] Sagum, R., Arcot, J., Effect of domestic processing methods on the starch, non-starch polyscaccharides, and in vitro starch and protein digestibility of three varieties of rice with varying levels of amylose. Food Chem. 2000, 70, 107111.

[12] Frei, M., Siddhuraju, K., Becker, K., Studies on the in vitro starch digestibility and the glycemic index of six different indigenous rice cultivars from the Philippines. Food Chem. 2003, 83, 395-402.

[13] Kim, J. C., Mullan, B. P., Hampson, D. J., Pluske, J. R., Effects of amylose content, autoclaving, parboiling, extrusion, and post-cooking treatments on resistant starch content of different rice cultivars. Aust. J. Agric. Res. 2006, 57, 1291-1296.

[14] Zhang, W. W., Bi, J. C., Yan, X. Y., Wang, H. L. et al., In vitro measurement of resistant starch of cooked milled rice and physicochemical characteristics affecting its formation. Food Chem. 2007, 105, 462-468.

[15] Hu, P., Zhao, H., Duan, Z., Zhang, L., Wu, D., Starch digestibility and the estimated glycemic score of different types of rice differing in amylose contents. J. Cereal Sci. 2004, 40, 231-237.

[16] Benmoussa, M., Moldenhauer, K., Hamaker, B., Rice amylopectin fine structure variability affects starch digestion properties. J. Agric. Food Chem. 2007, 55, 1475-1479.

[17] Jurs, P. C., Chemometrics and multivariate analysis in analytical chemistry, in: Lipkowitz, K. B., Boyd, D. B. (Eds.), Reviews in Computational Chemistry, Vol. I, VCH Publishers, New York 1990

[18] Juliano, B. O., A simplified assay for milled-rice amylose. Cereal Sci. Today 1971, 16, 334-340.

[19] AACC, Approved Methods of the AACC, American Association of Cereal Chemists, St. Paul, MN 2000.

[20] Cagampang, G. B., Perez, C. M., Juliano, B. O., A gel consistency test for eating quality of rice. J. Sci. Food Agric. 1973, 24, 1589-1594.

[21] Little, R. R., Hilder, G. B., Dawson, E. H., Differential effect of dilute alkali on 25 varieties of milled white rice. Cereal Chem. 1958, 35, 111-126.

[22] Champagne, E. T., Wood, D. F., Juliano, B. O., Bechtel, D. B., in: Champagne, E. T. (Ed.), Rice Chemistry and Technology, AACC International, St. Paul, MN 2004, pp. 77-107.

[23] Lai, V. M. F., Chen, M.-C., Yeh, A.-I., Juliano, B. O., Lii, C.-Y., Molecular and gelatinization properties of rice starches from IR 24 and Sinandomeng cultivars. Cereal Chem. 2001, 78, 596-602.

[24] Patindol, J. A., Wang, Y.-J., Fine structures and properties of starches from long-grain rice cultivars with different functionality. Cereal Chem. 2002, 79, 465-469.

[25] Todeschini, R., Consonni, V., Mauri, A., Pavan, M., Detecting bad regression models: multicriteria fitness functions in regression analysis. Anal. Chim. Acta 2004, 515, 199-208. 